\title{
Blepharoplasty Complications
}

\author{
William P. Mack, M.D., P.A. ${ }^{1}$ \\ ${ }^{1}$ Department of Ophthalmology, University of South Florida, Florida \\ Address for correspondence and reprint requests William P. Mack, \\ M.D., P.A., 3109 W. Azeele St., Tampa, Florida 33609 \\ Facial Plast Surg 2012;28:273-287 \\ (e-mail: drmack@tampabay.rr.com).
}
Abstract
Keywords
- blepharoplasty
- lid retraction
- orbital hemorrhage
- dry eye syndrome
- ptosis

There are three major areas of concern for a patient who has complications following a cosmetic blepharoplasty: cosmetic issues, functional issues, and uncomfortable/symptomatic issues or a combination of the above. An emphasis will be placed on avoiding cosmetic eyelid complications as well as the medical and surgical management of complications.
It is extremely valuable for the facial cosmetic surgeon to take the time with prospective patients to emphasize the aging changes that occur in the periocular region including loss of facial volume (deflation), shifting of tissues (descent), and changes in the skin/ligament/bone/and muscle. The cumulative effect of these aging changes in the eyelid region results in "baggy lids," suborbicularis oculi fat (SOOF) descent, eyelid/ brow ptosis, loss of skin elasticity, and subcutaneous fat loss. The goal of facial cosmetic surgery, particularly in the periorbital region, should focus on the restoration of fullness with avoidance of procedures/surgeries that result in a skeletonized, hollow appearance. To achieve this goal, the facial cosmetic surgeon should strive to reposition and reinforce facial tissues to achieve a natural facial aesthetic balance between the forehead, upper/lower eyelids, and midface. The facial cosmetic surgeon should not focus on the amount of tissue removed in cosmetic eyelid surgery but instead should focus on the importance of preservation of tissue to achieve optimal aesthetic surgical outcomes.

Complications following cosmetic eyelid surgery are divided into functional, cosmetic, or a combination of both. Included in postoperative functional issues following cosmetic eyelid surgery are orbital hemorrhage, keratopathy/dry eyes, infection, tearing/ocular irritation, lagophthalmos, loss of vision, and blindness (-Table 1).$^{1-5}$ Cosmetic complications, which can occur postoperatively, include hollowing, deep superior sulcus, lateral canthal dystopia, and chemosis. Complications, which present with both functional and cosmetic problems, include upper or lower eyelid malposition, brow/eyelid ptosis, and lid retraction (-Table $\mathbf{2}$ ).

\section{Eyelid Anatomy}

The facial cosmetic surgeon should have a thorough understanding of the normal eyelid anatomy. Shaped like an almond, the normal upper eyelid has the highest point just nasal to the pupil with the normal brow position higher temporally (-Fig. 1). The upper eyelid has a more arched contour than the lower eyelid and the palpebral fissure, defined as the distance between the upper and lower eyelids, is $\sim 10 \mathrm{~mm}$. The typical Caucasian upper eyelid crease is at $\sim 8$ to $9 \mathrm{~mm}$, where the uppermost fibers of the levator aponeurosis insert into the lamellae and subcutaneous tissue. The lateral commissure is 1 to $2 \mathrm{~mm}$ higher than the medial commissure with the horizontal length of the eyelids to be $30 \mathrm{~mm}$. The lower eyelid margin rests in apposition along the entire length of the eye. The eyelid is divided into three lamellae: anterior, middle, and posterior lamella. Skin and orbicularis muscle make up the anterior layer, the middle lamella is comprised of the orbital septum, and the posterior lamella includes tarsus and conjunctiva.

\section{History}

A detailed preoperative medical history should be obtained as it is important to identify prospective surgical candidates who may be at an increased risk for possible complications from cosmetic eyelid surgery. A history of systemic disease, such as Graves' disease, Sjögren's syndrome, rheumatoid arthritis, rosacea, Bell's palsy, and myasthenia gravis or other neuromuscular diseases should be documented and
Issue Theme Avoiding and Managing Complications in Facial Plastic Surgery; Guest Editor, Steven J. Pearlman, M.D., F.A.C.S.
Copyright (c) 2012 by Thieme Medical Publishers, Inc., 333 Seventh Avenue, New York, NY 10001, USA.

Tel: +1(212) 584-4662.
DOI http://dx.doi.org/ 10.1055/s-0032-1312705. ISSN 0736-6825. 
Table 1 Cosmetic Complications

1. Lower lid hollowing

2. Deep superior sulcus

3. Lid crease/fold asymmetry

4. Lateral canthal dystopia

5. Eyelid malposition

6. Ptosis

7. Asymmetry

8. Lid retraction

discussed at length with the patient. Any past history of ocular allergies, facial trauma, previous facial surgery including skin cancer excision, or any previous periocular procedures should also be identified and discussed.

A past history of LASIK (laser-assisted in situ keratomileusis) surgery is extremely important to obtain because these patients are at an increased risk for postoperative dry eye symptoms following cosmetic eyelid surgery. Following LASIK surgery, patients develop a transient neurotrophic keratopathy secondary to the severing of corneal nerves, which leads to a 15 to $25 \%$ chance of developing dry eyes. ${ }^{6}$ It is important to note that the normal corneal reflex arc is triggered by foreign body sensation or ocular irritation, which causes ocular surface desiccation leading to the subsequent blink reflex resulting in sweeping the cornea with tears. Following blepharoplasty, patients have a transient lagophthalmos, but the corneal reflex arc blinking pattern is increased to prevent or decrease dry eye symptoms. During LASIK surgery, transection of the corneal sensory nerves occurs and the normal blink reflex is blunted which results in decreased corneal sensitivity and a decreased blink rate, thus resulting in decreased tear production. ${ }^{7}$ Therefore, the combination of LASIK and blepharoplasty can potentially lead to a greater risk for the development of severe dry eye condition. An algorithm for the workup and possible treatment of patients with a history of prior LASIK who are planning to undergo blepharoplasty was developed by Korn et al. $^{7}$

\section{Brow/Upper Eyelid Examination}

In addition to the complete review of the patient's history, the prospective surgical candidate should have a complete periocular examination, including the brow, lid, and cheek regions as well as the ocular surface to avoid many of the

Table 2 Functional Complications
1. Dry eyes/keratopathy
2. Tearing/ocular irritation
3. Orbital hemorrhage/hematoma
4. Visual loss/blindness
5. Lagophthalmos
6. Chemosis
7. Lid retraction
8. Ptosis
9. Eyelid malposition

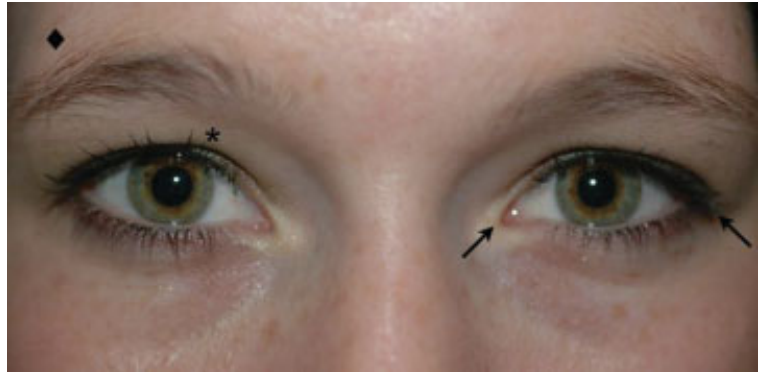

Figure 1 Normal almond-shaped eyelid, including normal margin reflex distance, lateral commissure 1 to $2 \mathrm{~mm}$ higher than medial commissure (arrow), the upper eyelid highest point just nasal to the pupil $\left({ }^{*}\right)$, and the brow position higher temporally (diamond).

complications that can occur following cosmetic blepharoplasty. Any preoperative asymmetry should be documented and discussed with the patient. The patient should undergo a complete ocular examination including documentation of vision, pupil exam, extraocular motility, and slit-lamp examination to evaluate corneal status. Any signs of ocular surface problems, dry eye syndrome, and blepharitis or eyelid inflammation should be documented and treated preoperatively.

The diagnosis of underlying brow ptosis is important for surgical planning as patients may exhibit contraction of the frontalis muscle in an attempt to raise the brows to correct underlying upper eyelid ptosis or significant dermatochalasis. An aged, tired appearance may result as the distance between the brow and lid margin is increased from this secondary brow compensation. Assessment of the eyelid-brow complex should be made with the patient in a sitting position. Unmasking of underlying brow ptosis is accomplished by applying manual pressure to immobilize the brow region while having the patient look in primary gaze (-Fig. 2 ). It is important to have an in-depth discussion with patients who have evidence of both brow ptosis and dermatochalasis, making certain that if the patient declines brow ptosis correction at the time of the planned blepharoplasty, then the final surgical aesthetic results may be compromised.

The examination should include documentation of the eyelid crease and position, evidence of preexisting lagophthalmos, floppy eyelid syndrome, deep superior sulcus, prolapsed lacrimal gland, and/or underlying eyelid ptosis. Evidence of eyelid ptosis is documented by the margin reflex distance (MRD1), which is defined as the distance from the corneal light reflex to the center of the upper eyelid as the patient gazes in primary position. The normal MRD1 in an adult is 1 to $2 \mathrm{~mm}$ below the superior corneal limbus in primary gaze (-Fig. 1). Many of the above-described issues can be addressed at the time of surgery and should be included in the surgical plan.

\section{Lower Eyelid/Cheek Examination}

Thorough evaluation of the lower eyelid/cheek region of the face is crucial as the vast majority of cosmetic eyelid surgery 


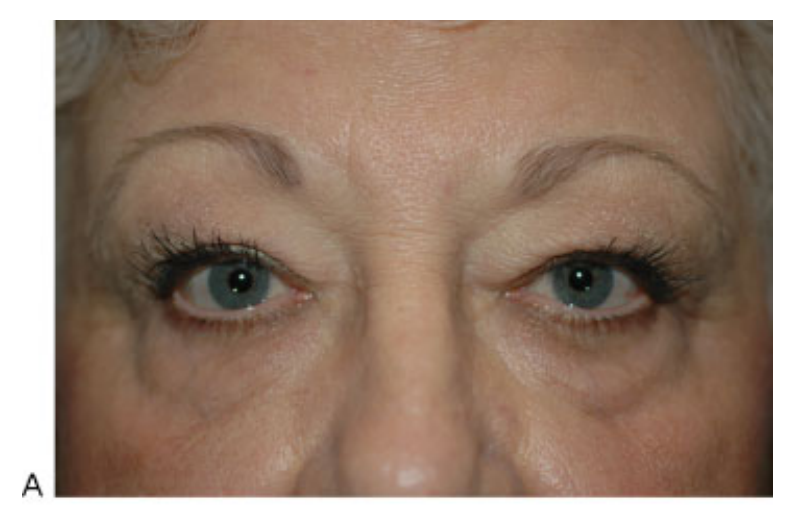

B

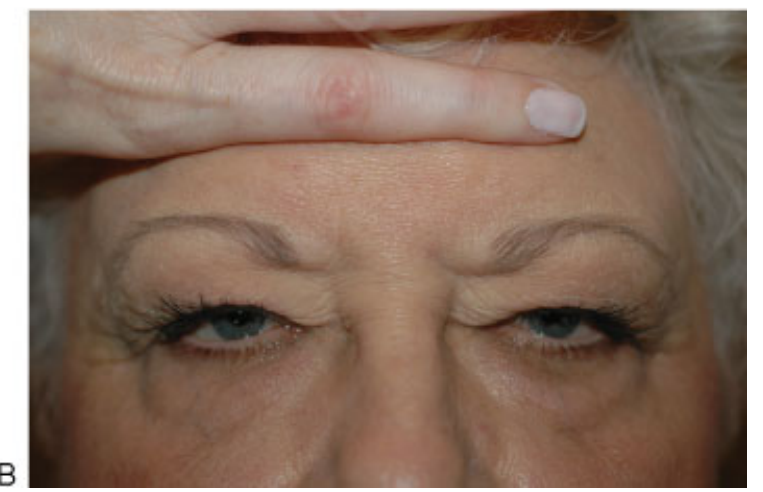

Figure 2 (A) Patients with underlying brow ptosis may have evidence of frontalis muscle contraction to raise the brows secondary to underlying upper eyelid ptosis or significant dermatochalasis. (B) To diagnose and unmask brow ptosis, manual pressure is applied to the brow region with the patient looking in primary gaze.

complications occur following lower eyelid blepharoplasty. Secondary to aging changes associated with deflation and descent of tissues, as well as loss of elasticity of the skin, the lower eyelid/cheek junction develops an uneven contour with increased prominence of lower eyelid fat resulting in a nasojugal fold and tear trough deformity. During the preoperative examination, patients should be evaluated for lower eyelid malposition, poor maxillary bony support with a negative facial vector, and lower eyelid laxity. Hester et al reported that patients were at an increased risk for postoperative lower lid malposition if there was preoperative evidence of enophthalmic orbits and significant horizontal lower lid laxity (-Table 3). ${ }^{8}$ Patients should also be evaluated for lagophthalmos, lower lid hollowing, stretching of the lateral canthal tendons, eyelid retraction, Bell's phenomenon, alter-

Table 3 Preoperative Identification of High-Risk Patients
1. Dry eye syndrome
2. Thyroid disease
3. Lower lid laxity
4. Negative vector
5. Scleral show
6. Previous facial trauma
7. Previous facial surgery
8. Psychological issues
9. Unrealistic expectations

ation in the tear film/blink reflex, ineffectiveness of the tearing lacrimal pump, evidence of corneal exposure, eyelid or punctal ectropion, inferior scleral show, and dry eye syndrome.

It is recommended that the preoperative lower eyelid evaluation include both the distraction test and the snapback test. During the distraction test, the eyelid is pulled anteriorly; if the distracted distance is greater than 6 to $8 \mathrm{~mm}$, then there is evidence of lower lid laxity, which should be addressed intraoperatively ( $\mathbf{- F i g}$. 3A). The snap-back test, which assesses orbicularis muscle function and the amount of lid tone, is performed by pulling the lower lid inferiorly toward the orbital rim and released. A normal test results when a fast "snap" of the lower eyelid to the proper position occurs, thus indicating normal lid tension, whereas poor snap-back test is evidence of poor lid tone (-Fig. 3B). It is also important to check for any evidence of preoperative lagophthalmos by having patients passively close their eyelids as if they were sleeping ( $\mathbf{- F i g . ~} \mathbf{3 C}$ ).

Lower eyelid retraction, which can be a very severe complication that occurs after cosmetic lower lid blepharoplasty, is defined as inferior malposition of the lower eyelid margin without eyelid eversion. The assessment for evidence of lower eyelid retraction is made by placing upward traction on the lower eyelid, which results in the lower eyelid being raised to at least the mid pupil level under normal conditions. Evidence of lower lid retraction exists if this level is not achieved with raising the lower eyelid (-Fig. 4). Lower lid retraction occurs secondary to inflammation, scarring, shortening, and cicatricial tethering of the middle and posterior lamellae.

\section{Management of Dry Eye Syndrome/Ocular Irritation}

Facial cosmetic surgeons must be aware of the long-term implications of eyelid surgery from both an aesthetic and functional standpoint to assure correct lid position and closure for adequate corneal protection and ocular lubrication. Ocular irritation following cosmetic eyelid surgery can occur from multiple etiologies including: dry eye syndrome, lid retraction, lower eyelid malposition, lagophthalmos, blepharitis, and alterations in the tear film and/or blink reflex. Typically, postoperative ocular irritation can be managed medically and with the tincture of time, thus avoiding any further surgical intervention. The preoperative diagnosis and treatment of dry eye syndrome is important as this diagnosis is very common, affecting up to $17 \%$ of women and up to $12 \%$ of men in the general population, with the incidence of dry eye syndrome following blepharoplasty between $8 \%$ and $21 \%{ }^{9-12}$

When obtaining the patient's history, it is important to ascertain risk factors for dry eye syndrome, including underlying systemic disease, menopause, previous lid surgery, and history of LASIK. ${ }^{13}$ In addition to obtaining a complete history, patients should be assessed preoperatively for possible dry eye syndrome with a Schirmer's test. The Schirmer strip is inserted in the lower eyelid at the lateral limbus after a topical 
A
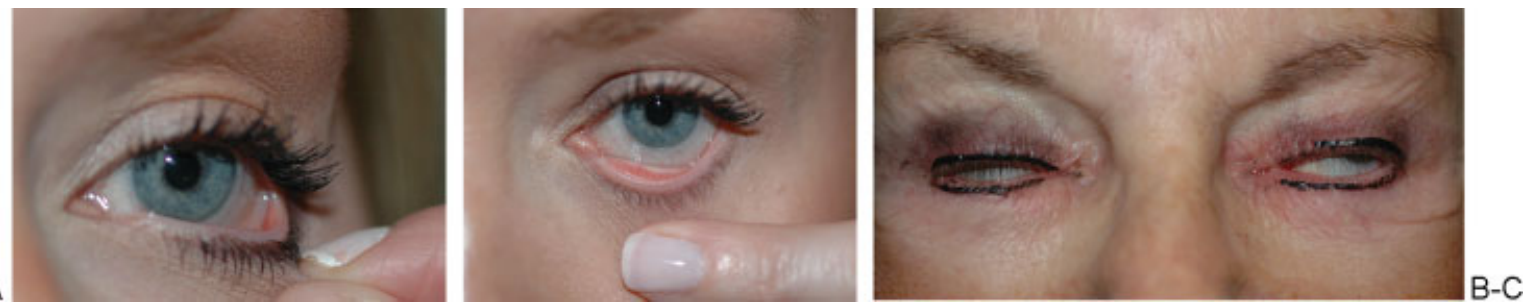

Figure 3 (A) The distraction test is performed by grasping the eyelid and pulling anteriorly, Lower lid laxity is present if the distracted distance is greater than 6 to $8 \mathrm{~mm}$. (B) The snap-back test, which is used to assess orbicularis oculi function and lower eyelid tone, is performed by displacing the lower eyelid inferiorly toward the orbital rim and releasing the lid. A slow return of the lid is indicative of decreased lid tone. (C) Patient presenting for revisional lid surgery with evidence of severe lagophthalmos secondary to upper and lower eyelid retraction after an overaggressive upper and lower lid blepharoplasty.

anesthetic drop has been placed onto the eye (-Fig. 5). The Schirmer strip is removed after 5 minutes with a normal values being between 10 to $15 \mathrm{~mm}$ of wetting. If the measurement is significantly less than $10 \mathrm{~mm}$, then the patient has evidence of dry eye syndrome secondary to hyposecretion of tears. Whereas the results of Schirmer's testing may be inconsistent at times, the test is beneficial to document evidence of severe dry eyes as this may prove to be a contraindication to upper eyelid blepharoplasty as these patients may experience worsening of their dry eye symptoms.

It is not uncommon for postoperative cosmetic blepharoplasty patients to have transient dry eye symptoms, which are typically mild in nature. Patients may note evidence of burning, dryness, stinging, foreign-body sensation, blurry
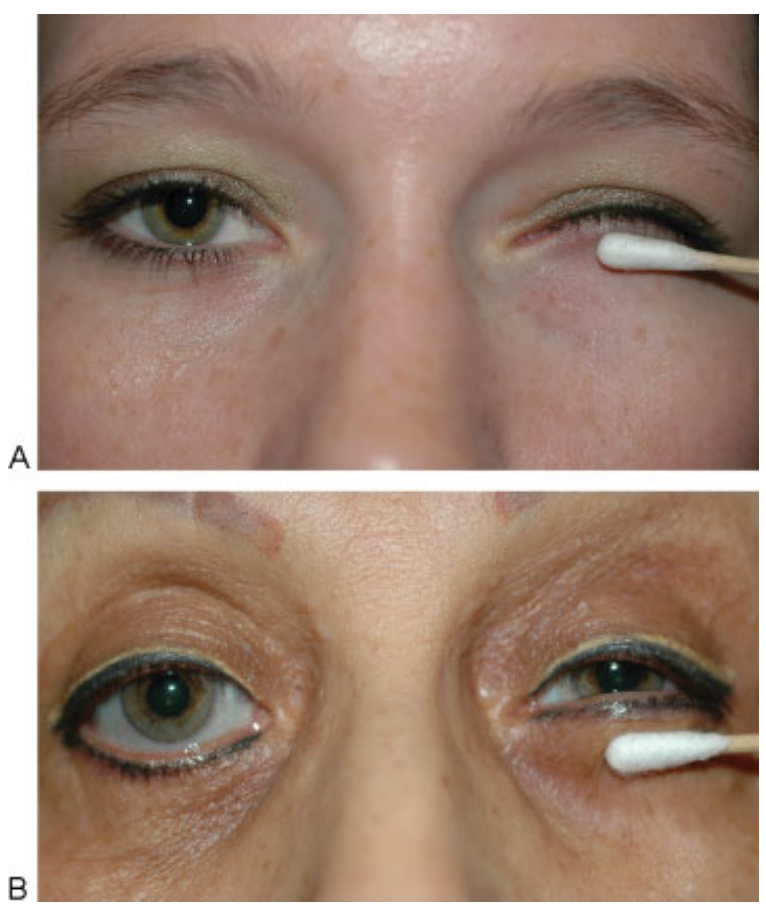

Figure 4 Lower lid retraction is defined as inferior malposition of the lower eyelid margin without eyelid eversion and is diagnosed by placing upward traction on the lower eyelid. (A) Normally the lower lid can be displaced to the midpupil or above. (B) The vertical displacement of the lower lid is restricted in this patient with evidence of lid retraction, scleral show, and lateral canthal dystopia. vision, photophobia, itching, and redness. It should be noted that ocular surface lubrication can be influenced by both alteration of the quantitative and qualitative components of the tear film, as well as tear distribution problems secondary to a poor blink reflex mechanism. Quantitative deficiencies result from decreased tear production whereas qualitative problems are secondary to blepharitis/meibomitis affecting the mucous and lipid layers of the tear film, which leads to evaporation of the tear film.

Three components are responsible for normal tearing ${ }^{1}$ : production and release of tears from the lacrimal gland and accessory glands, ${ }^{2}$ blinking and distribution of tears, ${ }^{3}$ and tear pumping into the lacrimal drainage system. The importance of the action of the orbicularis oculi cannot be overemphasized as this muscle is responsible for the second two components for normal tearing. ${ }^{14}$ Although the preoperative diagnosis and treatment of dry eye syndrome are important, intraoperative measures such as preservation of the orbicularis oculi muscle and its innervation may allow blepharoplasty to be performed safely in patients with dry eye syndrome. ${ }^{14}$ With preservation of the orbicularis muscle and its innervation, the dynamics of eyelid closure, including tear pumping and tear distribution, are not affected. The importance of the preservation of the orbicularis muscle is not only important functionally, but also from a cosmetic

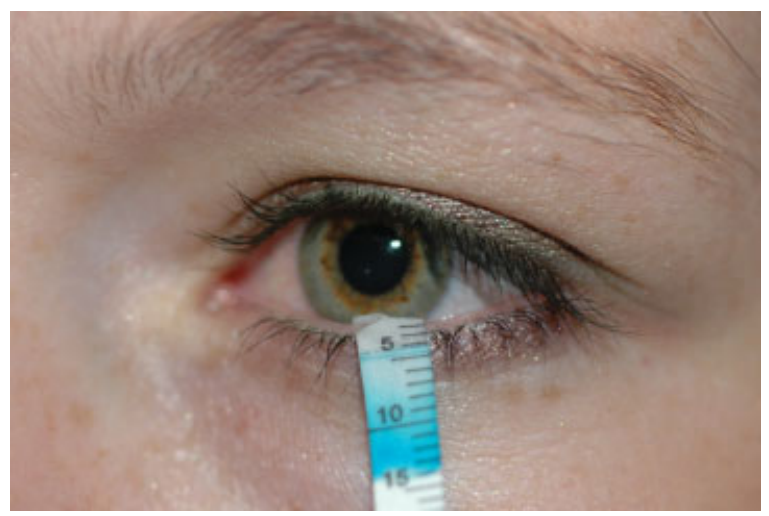

Figure 5 Following topical anesthetic, the Schirmer's strip is inserted at the lateral limbus and removed after 5 minutes with the normal range being between 10 to $15 \mathrm{~mm}$. If the test is significantly less than $10 \mathrm{~mm}$, then the patient has evidence of dry eye syndrome secondary to tear hyposecretion. 
standpoint by retaining a youthful fullness to the periorbital region. ${ }^{15}$

With preservation of the orbicularis muscle and its innervations in transconjunctival lower lid blepharoplasty, there is a decreased incidence of complications of lid retraction, scleral show, and lacrimal pump problems as compared with the external skin-muscle flap technique. When performing transconjunctival lower lid blepharoplasty, either a pinch technique or laser resurfacing can be used to address lower lid rhytids.

Facial cosmetic surgeons should strive to diagnose dry eyes preoperatively and attempt to maximize comfort through various treatment options. Medical options for the treatment of dry eye syndrome to decrease ocular irritation include: lubrication (artificial tears/ointment), tapering topical steroids, nonsteroidal anti-inflammatory drugs, and topical cyclosporine (Restasis (Allergan, Irvine, CA)). In addition to the topical treatments, the insertion of collagen/silicone punctual plugs may also prove to be beneficial. Doxycycline, flax seed oil, omega-3 fatty acids, and warm compresses/ scrubs can be used for the treatment of blepharitis/meibomitis. Patients who have planned eyelid revision surgery may also benefit from the initiation of the described treatment regimens. Preexisting conditions, such as lid malposition, lid laxity, and lid retraction, can be corrected during the planned surgical procedure.

\section{Management of Orbital Hemorrhage}

The most devastating complication of cosmetic eyelid surgery is an orbital hemorrhage with resulting loss of vision or even blindness. Hass et al reported the risk of orbital hemorrhage to be 1 in 2000 and the risk of orbital hemorrhage with visual loss as 1 in $10,000 .{ }^{16}$ Comorbidities for development of orbital hemorrhage include history of hypertension, preoperative aspirin, postoperative vomiting, and postoperative physical activity. ${ }^{16}$ The authors also noted an increased risk of orbital hemorrhage during the first 3 hours following blepharoplasty surgery, with the risk decreasing 24 hours after surgery. ${ }^{16}$

Risk factors for orbital hemorrhage, which should be ascertained during the patient's history, include history of hypertension, medications that have antiplatelet or anticoagulant properties including homeopathic or herbal medications, history of abnormal bruising or bleeding, or any underlying disease that may contribute to bleeding. ${ }^{16,17}$ Preoperatively, patients should be provided with a list of medications, which my surgical coordinator frequently updates, that should be discontinued including coumadin, aspirin, nonsteroidal anti-inflammatory drugs, Vitamin E, omega 3 fatty acids, garlic, and other supplements or herbs with blood thinning effects (-Fig. 6). Arnica montana, vitamin K, and bromelain can also be implemented preoperatively to limit postoperative edema and ecchymoses.

Intraoperatively, facial cosmetics surgeons should wait 10 to 15 minutes following the administration of the local anesthesia to allow the maximum vasoconstrictive effects of the epinephrine and should also closely control the blood pressure. Meticulous dissection of the orbital fat pads is recommended to decrease the risk of posterior orbital bleed- ing. Careful attention to cauterization of any pinpoint areas of bleeding from the orbicularis muscle should be completed prior to closure of the skin.

Early detection is critical for the treatment of orbital hemorrhage, therefore postoperative checking of vision is recommended and patients should be encouraged to immediately report any signs of decreased vision, diplopia, pain, or rapidly increasing edema (- Table 4). ${ }^{18-24}$ Patients are instructed to avoid bending, lifting, and straining and are encouraged to sleep with their head elevated and to apply ice packs for 2 to 3 days postoperatively. If patients experience any of the previously mentioned signs/symptoms, the surgeon should examine the patient in a timely fashion for evidence of visual loss, proptosis, relative afferent pupillary defect, and/or decreased extraocular motility (-Fig. 7). The surgeon's treatment goal is to decrease orbital pressure to restore blood flow to the eye. Initially, the surgeon should open the eyelid incision to identify any active bleeding sites followed by lateral canthotomy and cantholysis (- Figs. 8A, 8B). It is extremely important to lyse any adhesions to the orbital rim to allow the lower eyelid to be completely mobile. Active bleeding sites should be meticulously cauterized with subsequent drainage of any hematomas. In very rare circumstances, an orbital decompression may be necessary. Once the patient is stabilized, a tapering dose of systemic steroids can be started and the patent should be referred to an ophthalmologist for assessment of retinal perfusion. If increased intraocular pressure is diagnosed, the ophthalmologist may start a treatment regimen of topical or oral glaucoma agents. The patient should then be monitored for visual acuity, pupil examination, and intraocular pressure.

\section{Botulinum Toxin}

During the preoperative consultation, it is imperative that facial cosmetic surgeons obtain the past history of administration of botulinum toxin in our prospective cosmetic eyelid surgery patients as this can affect surgical planning. The specific treated area should be documented and it also should be ascertained whether the patient will continue the use of botulinum toxin following the planned surgery. Complications secondary to botulinum toxin treatments include diplopia, lower lid ectropion, eyebrow ptosis, upper eyelid ptosis, and asymmetrical results.

The most common complication from the administration of botulinum toxin is upper eyelid ptosis, which occurs secondary to migration from periocular injection sites through the orbital septum to the levator muscle of the upper eyelid. Fortunately, the ptosis is typically mild and improves with tincture of time. For the patient who is concerned with the ptosis, the cosmetic surgeon can treat this complication with the administration of apraclonidine $0.5 \%$ or a selective $\alpha-2$ adrenergic agonist, such as Naphcon (Alcon, Fort Worth, TX) or Alphagan (Allergan, Irvine, CA). The mechanism of action of these medications is the resultant effect on Mueller's muscle to raise the lid 1 to $2 \mathrm{~mm} .^{25,26}$ These topical medications can typically be tapered after 6 to 8 weeks as the effect of the botulinum toxin will be decreased at that time frame. 


\section{***PLEASE AVOID THESE MEDICATIONS FOR AT LEAST 10 DAYS BEFORE SURGERY*** \\ Orally Administered medications That Increase Bleeding Time \\ Preparations that contain nonsteroidal anti-inflammatory agents}

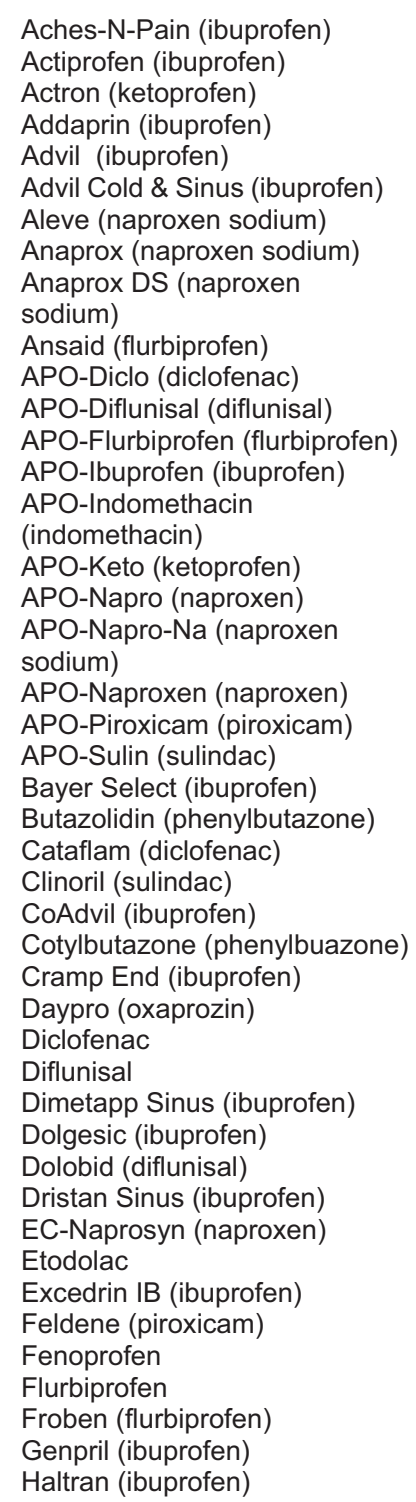

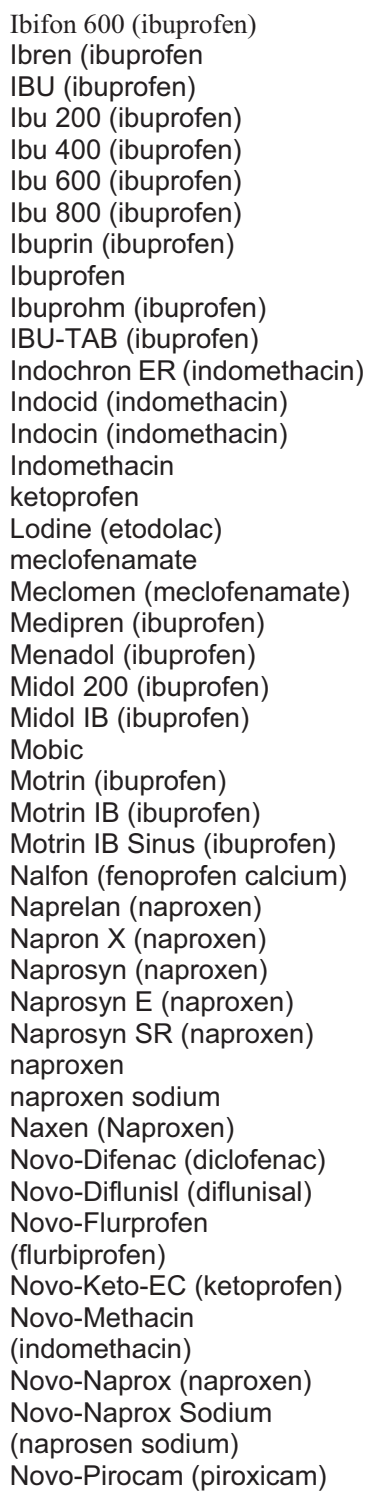

Novo-Profen (ibuprofen)

Novo-Sundac (sulindac)

Novo-Tolmetin (tolmetin)

Nu-Diclo (diclofenac)

Nu-Flubiprofen

(flurbiprofen)

Nu-lbuprofen (ibuprofen)

Nu-Indo (indomethacin)

Nu-Naprox (naproxen)

Nu-Pirox (piroxicam)

Nuprin (ibuprofen)

Nu-Sulindac (sulindac)

Orudis (ketoprofen)

Orudis E (ketoprofen)

Orudis KT(ketoprofen)

Orudis SR (ketoprofen)

Oruvail (ketoprofen)

Pamprin-IB (ibuprofen)

PediaProfen(ibuprofen)

Piroxicam

Ponstan (mefenamic acid)

Ponstel (mefenamic acid)

Q-Profen (ibuprofen)

Relafen (nabumetone)

Rhodis (ketoprofen)

Rufen (ibuprofen)

Saleto-200 (ibuprofen)

Saleto-400 (ibuprofen)

Saleto-600 (ibuprofen)

Saleto-800 (ibuprofen)

Sine-Aid IB (ibuprofen)

sulindac

Synflex (naproxen)

Synflex SR (naproxen)

Tolectin (tolemetin sodium)

tolmentin

Toradol (ketorolac)

Trendar (ibuprofen)

Ulraprin (ibuprofen)

Unipro (ibuprofen)

Valprin (ibuprofen)

Voltaren (diclofenac)

Voltaren Rapide

(diclofenac)

Voltaren SR (diclofenac)

Figure 6 List of blood-thinning, including over-the-counter, medications that patients are instructed to discontinue before their cosmetic eyelid surgery.

The facial cosmetic surgeon can also utilize botulinum toxin preoperatively to augment surgical results, such as in treating the brow depressors (corrugators, procerus, and lateral orbicularis oculi) 1 to 2 weeks prior to a planned endoscopic brow lift to decrease the action of the brow depressors during the postoperative period. The treatment of brow asymmetry can also be accomplished by the selective administration of botulinum toxin in the brow elevators (frontalis muscle) to lower brow position and in the lateral brow depressors (orbicularis oculi) to raise brow position (-Fig. 9). ${ }^{27,28}$ It is recommended to avoid botulinum toxin injections during facial surgical procedures secondary to the possible risk of diffusion. Injections in the crow's-feet region should be made subcutaneously to decrease the risk of bruising from the orbicularis oculi muscle. Advanced techniques for botulinum toxin include the administration of subdermal injections in the pretarsal orbicularis oculi at the extreme medial and lateral areas of the upper eyelid for the treatment of minimal to moderate ptosis. ${ }^{29}$

\section{Chemosis}

Postoperative chemosis following cosmetic blepharoplasty typically resolves spontaneously in most patients, but a small minority of patients can have moderate to severe symptoms, including foreign body sensation, irritation, pain, redness, 


\section{***PLEASE AVOID THESE MEDICATIONS FOR AT LEAST 10 DAYS BEFORE SURGERY*** \\ Orally Administered medications That Increase Bleeding Time \\ Preparations that contain nonsteroidal anti-inflammatory agents}

217

217 Strong

4-Way Cold tablets

Acuprin 81 (aspirin)

Adult Analgestic pain reliever

Aggrenox

Alka-Seltzer

Anacin

Analval

Anodynos

Antidol

APAC Improved

APO-ASA

APO-ASEN

Arco Pain

Arthrisin

Arthritis Pain Formula

Artria SR

ASA

Ascriptin

Aspercin

Aspergum

Aspermin

Asprin

Aspirin with codeine

Aspir-Low

Aspir-Tab

Aspirtab Max

Astone

Astrin

Axotal

Azdone tablets

B-A-C tablets

Bayer Aspirin

Bayer children's cold tablets

BC powder

BC Tablets

Buffaprin

Buffasal

Bufferin

Buffets II

Buffex

Buffinol

C2

Calamine

Cama arthritis pain reliever

Carisoprodol compound tablets

Children's aspirin

Cope

Coryphen

\begin{tabular}{|c|c|}
\hline Damason-P & Neogesic \\
\hline Darvon compound & Nervine \\
\hline Darvon compound-65 & Night-time Effervescent cold tablets \\
\hline Darvon with ASA & Norgesic \\
\hline Darvon-N with ASA & Norgesic Forte \\
\hline Dasin & Norwich extra-strength aspirin \\
\hline Dolcin & Novasen) \\
\hline Dolomine & Orphenagesic \\
\hline Dolprn \#3 tablets & Orphenagesic Forte \\
\hline Drinophen & Oxycodone and aspirin \\
\hline Duradyne & P-A-C \\
\hline Easprin & Pain Aid \\
\hline Ecotrin & Pain reliever tablets \\
\hline Emagrin & Panodynes \\
\hline Empirin & Pepto-Bismol \\
\hline Empirin with codeine & Percodan \\
\hline Entrophen & Percodan-Demi \\
\hline Equagesic & Persistin \\
\hline Equazine-M & Phenetron compound \\
\hline Excedrin & PMS with ASA \\
\hline Fiogesic tablets & Presalin \\
\hline Fiorgen PF & Propoxyphen compound \\
\hline Fiorinal & Propoxyphen napsylate with ASA \\
\hline Fiorinal with codeine & Quiet World tablets \\
\hline Gelpirin tablets & Rhinoceps \\
\hline Gemnisyn & Robaxisal tablets \\
\hline Genaced & Roxiprin \\
\hline Genacote & Roxiprin tablets \\
\hline Genprin & Salabuff \\
\hline Gensan & Salatin \\
\hline Goody's extra strength & Saleto \\
\hline Goody's Headache powder & Salocol \\
\hline Halfprin & Sine-Off sinus medicine tablets \\
\hline Headache tablet & Sloprin \\
\hline Heathprin & Soma compound tablets \\
\hline Herbopyrine & Soma compound with codeine \\
\hline Instantine & St. Joseph \\
\hline Isollyl Improved & Stanback powder \\
\hline Kalmex & Supac \\
\hline Lanorinal & Synalgos-DC capsules \\
\hline Lortab with ASA & Talwin compound \\
\hline Magnaprin & Tenol-Plus \\
\hline Marnal & Trigesic \\
\hline Measurin & Tri-Pain \\
\hline Micrainin & Ursinus Inlay-Tabs \\
\hline Meprobamate and aspirin & Valesin \\
\hline Meprogesic Q & Vanquish \\
\hline Midol for cramps, maximum strength & Verin \\
\hline Midol Original & Wesprin Buffered \\
\hline tum mus & Zorprin \\
\hline
\end{tabular}

Figure 6 Continued.

Table 4 Orbital Hemorrhage Warning Signs/Symptoms
1. Orbital pain
2. Loss of vision
3. Diplopia
4. Proptosis
5. Relative afferent pupillary defect
6. Limited extraocular motility
7. Increased orbital pressure/tense orbit

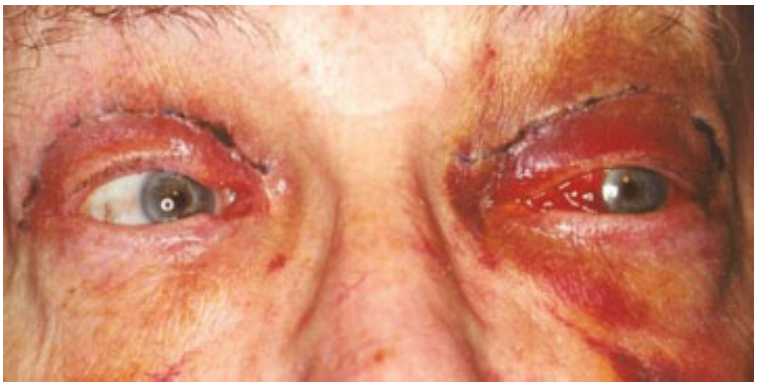

Figure 7 Patient presented with postoperative left orbital hemorrhage with pain, proptosis, relative afferent pupillary defect, and limited extraocular motility (-Fig. 11). 

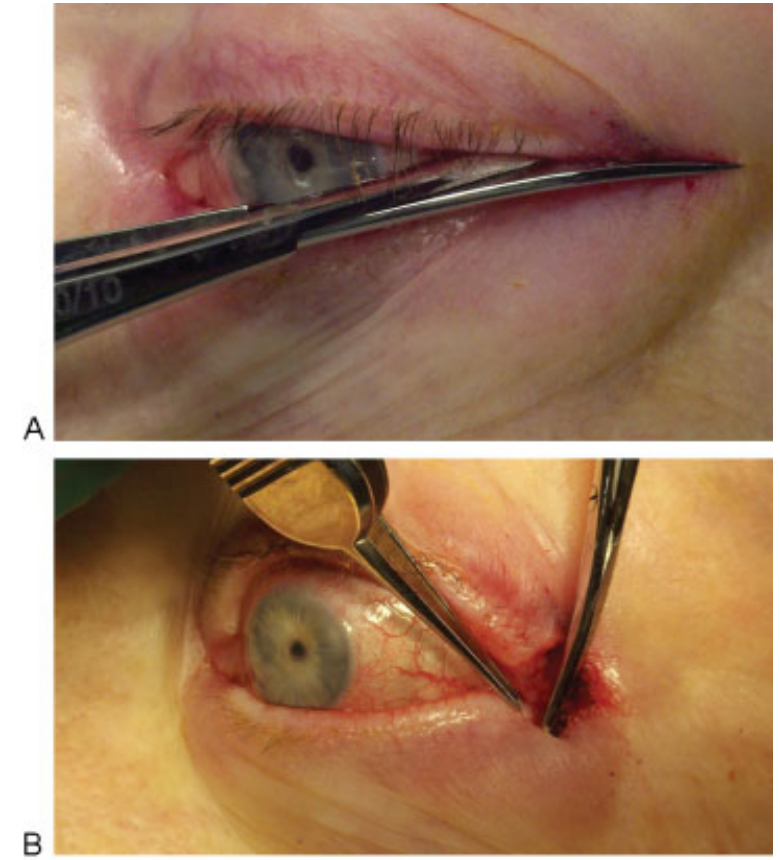

B

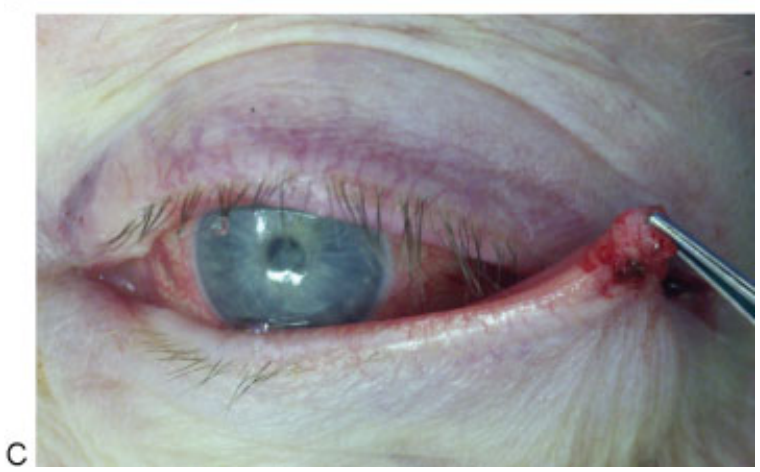

Figure 8 The treatment of orbital hemorrhage, which requires relieving orbital pressure to allow normal blood flow to the eye, is accomplished with a lateral canthotomy and cantholysis to allow the lower lid to be freely mobile (A, B, C).

epiphora, and blurred vision. Chemosis, which is defined as transudative edema of the bulbar and/or palpebral conjunctiva, presents as a visible yellowish or pink swelling of the conjunctiva. ${ }^{30}$ Multifactorial causes contribute to postoperative chemosis including exposure, prolonged postoperative inflammation, facial and periorbital edema, extensive surgical conjunctival manipulation, and postoperative disruption/ dysfunction of the lymphatic system. ${ }^{30-33}$ Periorbital and facial edema can result in secondary regional lymphatic stasis that can both trigger and cause worsening of chemosis, as the lateral half of the eyelid lymphatic system drains to the preauricular node and the medial half drains to the submandibuar node. ${ }^{30}$ Structural damage that occurs intraoperatively to the lymphatic channels that drain the conjunctiva can also cause lymphatic dysfunction. ${ }^{30,34}$

Predisposing factors for postoperative chemosis include increased surgical time resulting in increased periorbital swelling and exposure of the conjunctiva as well as lagophthalmos from upper eyelid blepharoplasty and/or brow-lift procedures. ${ }^{30}$ For most patients, postoperative chemosis will resolve spontaneously during the early postoperative period, but in some instances, a combination of pharmacological, mechanical, and/ or surgical therapies may be necessary for treatment. The facial cosmetic surgeon should focus on the importance of prevention of chemosis following cosmetic blepharoplasty by minimizing intraoperative risk factors with appropriate timely therapeutic intervention for persistent postoperative chemosis. ${ }^{30}$

Recommendations to decrease the risk of chemosis include frequent ocular lubrication intraoperatively, limited surgical dissection, intermittent forced eyelid closure, and temporary tarsorrhaphy suture. ${ }^{30}$ Treatment of postoperative chemosis includes medical therapies, mechanical compression, and surgical modalities if needed. Lubrication, topical steroids, head elevation, and eye patching are initiated, and if resolution of the chemosis is not complete, then drainage conjunctivotomy and temporary tarsorrhaphy may be utilized. ${ }^{30,31}$ Putterman advocates the utilization of patient finger compression 4 to 10 times per day as the patient manually elevates the lower eyelid over the chemotic area and applies pressure for $\sim 10$ seconds (-Fig. 10). ${ }^{35}$

\section{Management of Upper Eyelid Blepharoplasty/Ptosis Surgery/Brow Surgery}

To decrease or avoid complications from upper eyelid blepharoplasty, surgeons should strive for a natural, volume-
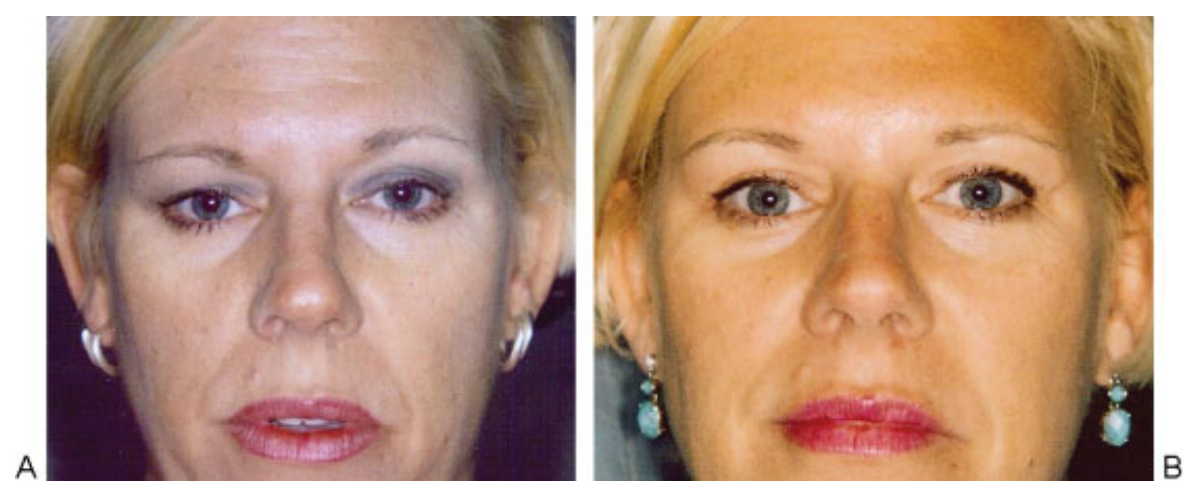

Figure 9 Botulinum toxin can be utilized to correct brow asymmetry. (A) Patient with evidence of brow asymmetry, left higher than right. (B) Same patient following the use of botulinum toxin to selectively lower the left brow and raise the right brow combined with upper eyelid blepharoplasty. 


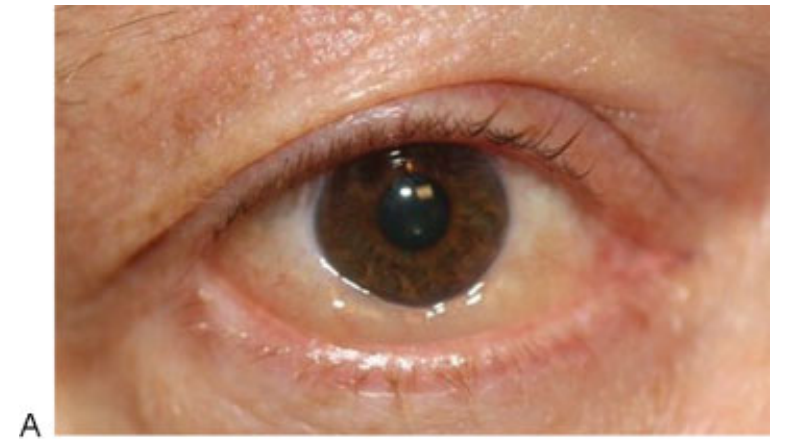

A

B

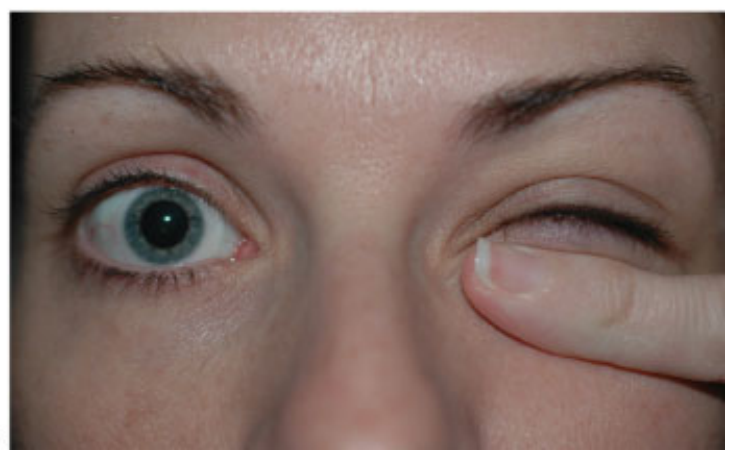

Figure 10 (A) Evidence of chronic chemosis following cosmetic lower lid blepharoplasty. (B) To treat chemosis, finger compressions can be performed by manually elevating the lower lid over the chemotic area and applying pressure for $\sim 10$ seconds.

sparing approach with attention to reestablishment of the upper eyelid. It is beneficial for one to keep in mind Flower's rule of preserving at least $20 \mathrm{~mm}$ of upper eyelid skin for normal lid function. ${ }^{36}$ During the evaluation, upper eyelids should be assessed for asymmetry of the lid crease/fold. Asymmetry of the lid crease can be a challenging issue, particularly trying to lower a crease that is too high, which may occur secondary to an iatrogenic cavity from excessive fat removal. Supernatural fixation may be utilized to raise a low crease by placing a three-point suture through the lower lip of the skin/orbicularis muscle incision, through levator aponeurosis, and then exiting through the upper lip of the skin/ orbicularis muscle incision.

Intraoperatively, the diagnosis of prolapse of the lacrimal gland, noted to be a firm, fibrous gray structure, can be made and corrected by resuspension to the periosteum of the superior orbital rim. ${ }^{37,38}$ Another potential complication of upper eyelid blepharoplasty is medial canthal webbing, which results from either an improperly placed incision or excessive skin removal. To decrease the risk of medial canthal webbing, the incision is angled slightly superior at the medial extent of the incision without extending past the level of the superior pomatum. Treatment includes massage initially, with surgical procedures such as Z-plasty as necessary.

Included in the evaluation is the assessment for underlying brow ptosis, which can be surgically repaired at the same time as the planned blepharoplasty (- Figs. 11, 12). Possible complications of endoscopic brow surgery include alopecia, numbness, facial nerve injury, and asymmetry. Meticulous attention to operating in the correct tissue plane during surgery with limited cauterization of the wound during
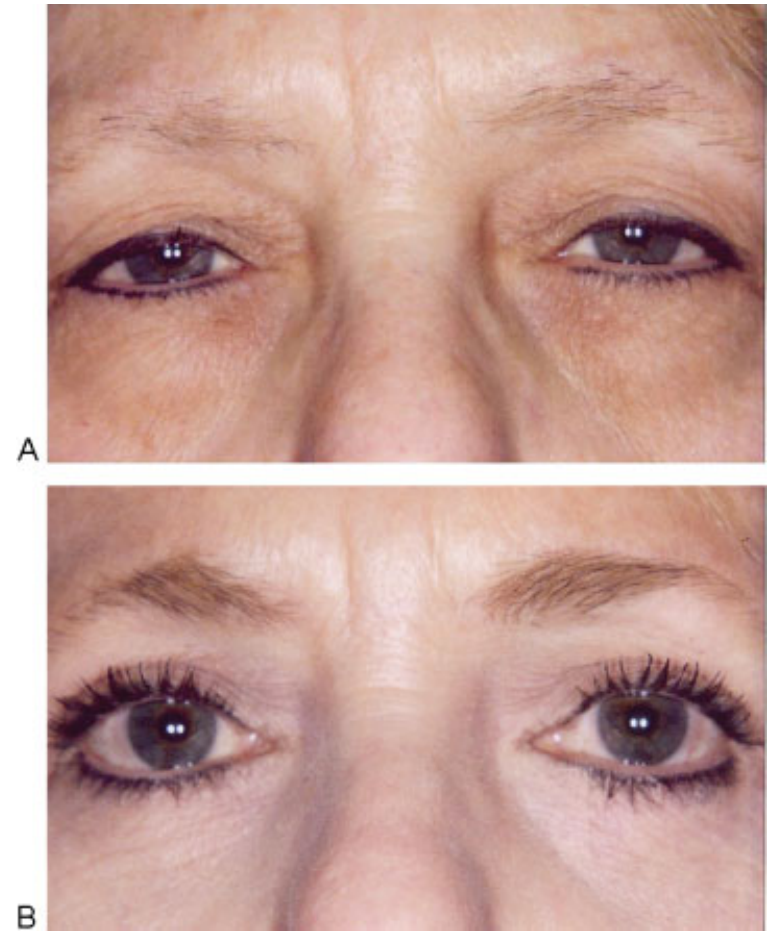

Figure 11 (A) Underlying lid ptosis, which should be corrected during the planned blepharoplasty, is evident in addition to dermatochalasis in this woman. (B) Same patient after combined bilateral upper eyelid blepharoplasty and levator advancement.
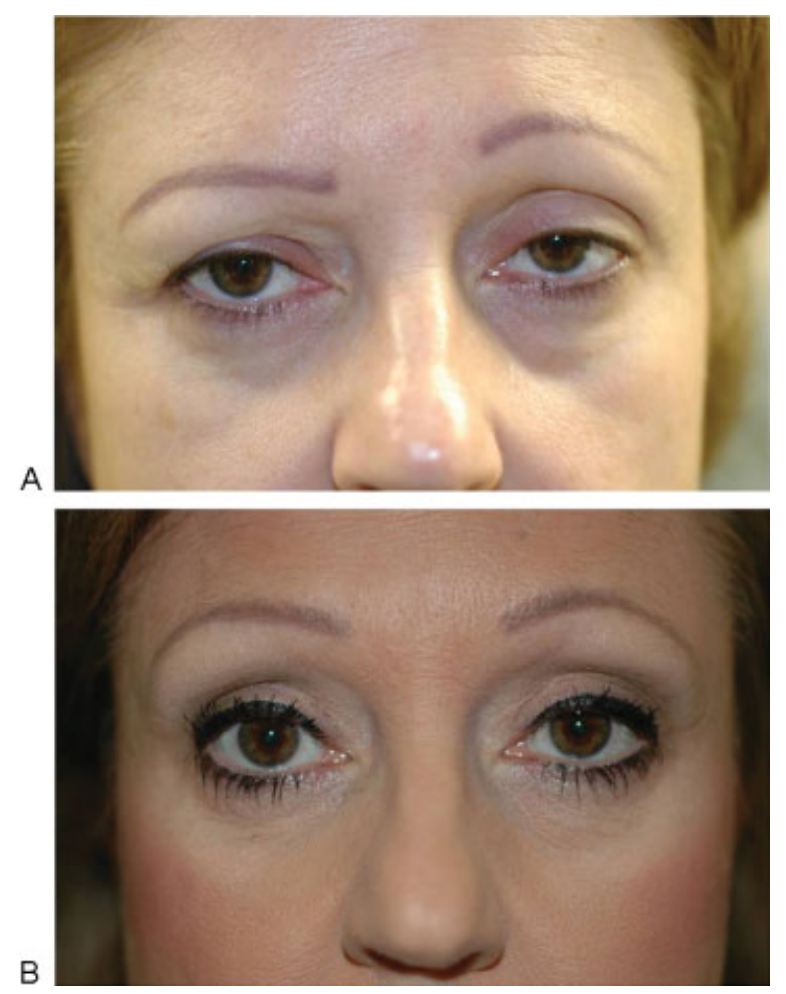

Figure 12 (A) Underlying brow ptosis and lid ptosis should also be corrected during the planned blepharoplasty. (B) Same patient following combined brow and eyelid surgery. 


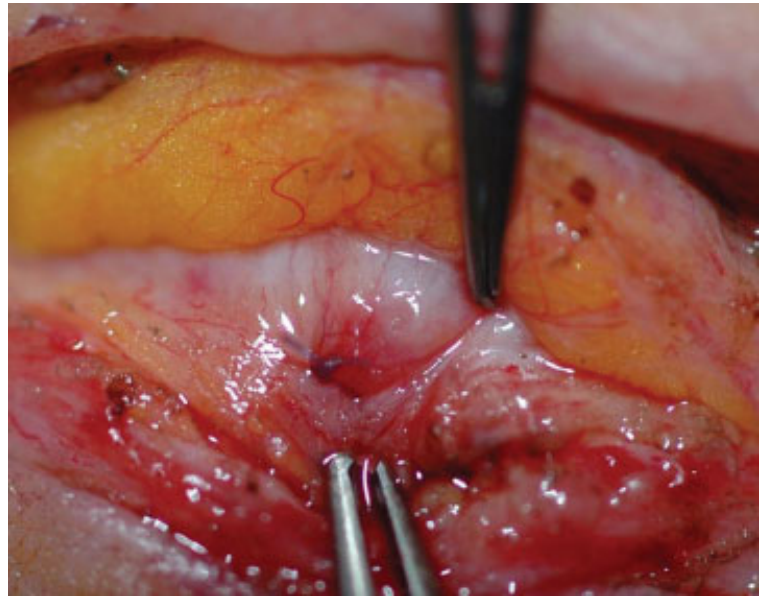

Figure 13 During levator advancement, it is important to dissect and enter the orbital septum superiorly to avoid the close attachment of the levator to the lower lip of the incision, and the central anterior tarsus should be exposed with placement of the suture in the central $5 \mathrm{~mm}$ of the tarsus and in the upper one-third of the tarsus as lower placement may result in ectropion.

closure are paramount to achieving superior aesthetic results in endoscopic brow-lift surgery

Preoperatively, any evidence of upper eyelid ptosis, particularly with secondary brow compensation, should be diagnosed and subsequently repaired during the blepharoplasty surgery. During the upper eyelid blepharoplasty, the surgeon should evaluate for any evidence of ptosis secondary to levator dehiscence and perform correction at that time. It is important for the surgeon to be aware of the close proximity of the levator aponeurosis to the inferior lip of the upper blepharoplasty incision to avoid damage, as this is the insertion point for the levator aponeurosis to the orbicularis muscle/skin. If the surgeon would inadvertently place his incision too deep, then dehiscence of the levator aponeurosis could result in ptosis. ${ }^{39}$ To further decrease the risk of iatrogenic damage to the levator aponeurosis, incisions through the orbital septum into the preaponeurotic fat pads should be made near the superior lip of the upper blepharoplasty incision while tenting the orbital septum 90 degrees from the levator aponeurosis.

Multiple etiologies can contribute to postblepharoplasty ptosis, including unrecognized preoperative ptosis, direct levator damage, stretching of the levator, and tethering secondary to the orbital septum being inadvertently incorporated into the eyelid closure. Surgical correction of ptosis is accomplished by either levator advancement or Muller's muscle-conjunctival resection. ${ }^{40,41}$ In levator advancement repair, the suture is placed in the central $5 \mathrm{~mm}$ of the tarsus, preferably in the upper third of the tarsus, as lower placement could potentially result in ectropion ( $\mathbf{F i g . 1 3}$ ).

\section{Management of Deep Superior Sulcus}

The presence of a deep superior sulcus results in a senile, aged appearance. Superior sulcus deepness is determined by the interplay between the brow fat, preaponeurotic fat pads, orbital septum, and the levator aponeurosis. Facial cosmetic surgeons should focus on achieving a natural brow contour with a full upper eyelid sulcus. An emphasis should be made to avoid the creation of a lid crease that is too high to avoid a deep superior sulcus. Options to correct the deep superior sulcus include ptosis repair, fat repositioning, alteration of the brow position with botulinum toxin, fat grafts, facial fillers, or dermis fat graft to add volume.

\section{Management of Lower Lid Hollowing}

Lower eyelid hollowing can occur secondary to aggressive lower lid blepharoplasty, aging changes related to soft tissue atrophy, thinning of the skin, soft tissue descent, and/or orbital fat herniation. ${ }^{42,43}$ The goal of treatment is to replace volume in this region through autologous fat, transposition of orbital fat, or dermal facial fillers such as hyaluronic acid ${ }^{42-53}$ (-Figs. 14, 15). The placement of the dermal facial fillers should be in a deep, supraperiosteal plane to reduce visibility in this thin tissue. ${ }^{47} \mathrm{~A}$ Tyndall effect can occur from superficial injection of the hyaluronic acid fillers resulting in a bluish color. This complication can be treated by either the injection of hyaluronidase or by using a No. 11 blade to nick the papule. ${ }^{42}$ Hyaluronidase can also be utilized for the treatment of any postinjection irregularity or asymmetry ( $\mathbf{F i g . ~ 1 6 ) . ~}$ Nitropaste should be available for the treatment of vascular compromise noted during facial filler treatments.

\section{Management of Lower Eyelid Retraction/ Lagophthalmos}

Lower eyelid retraction, defined as inferior malposition of the lower eyelid margin without eyelid eversion, is assessed by

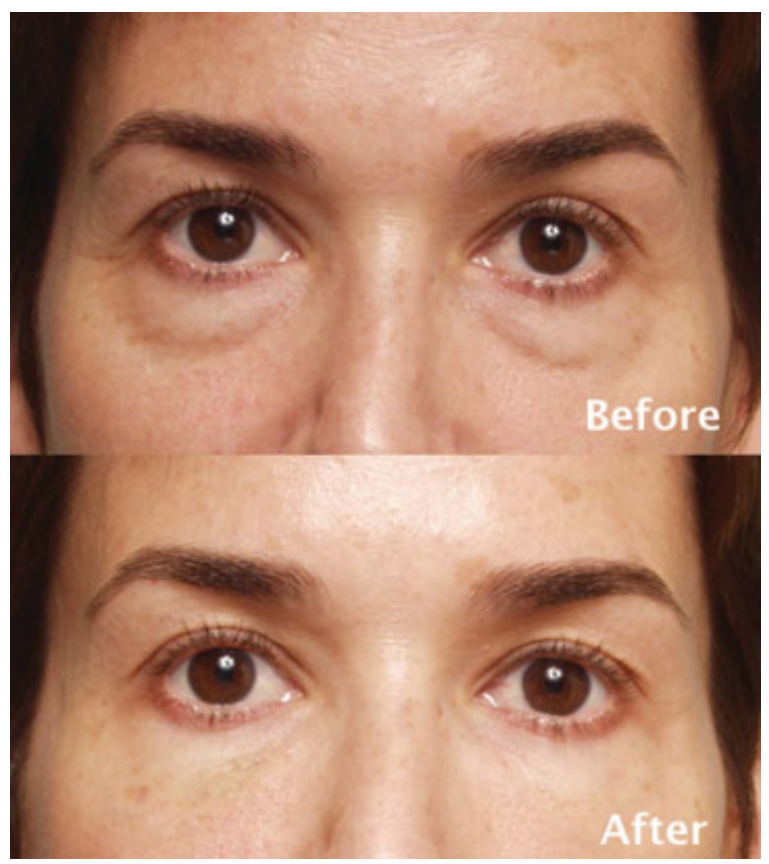

Figure 14 (A) Before and (B) after photos of a 40-year-old woman following treatment of bilateral lower eyelid hollowing with hyaluronic acid filler. (Kenneth D. Steinsapir, M.D., Inc. is the copyright holder and permission is being granted to use the images.) 


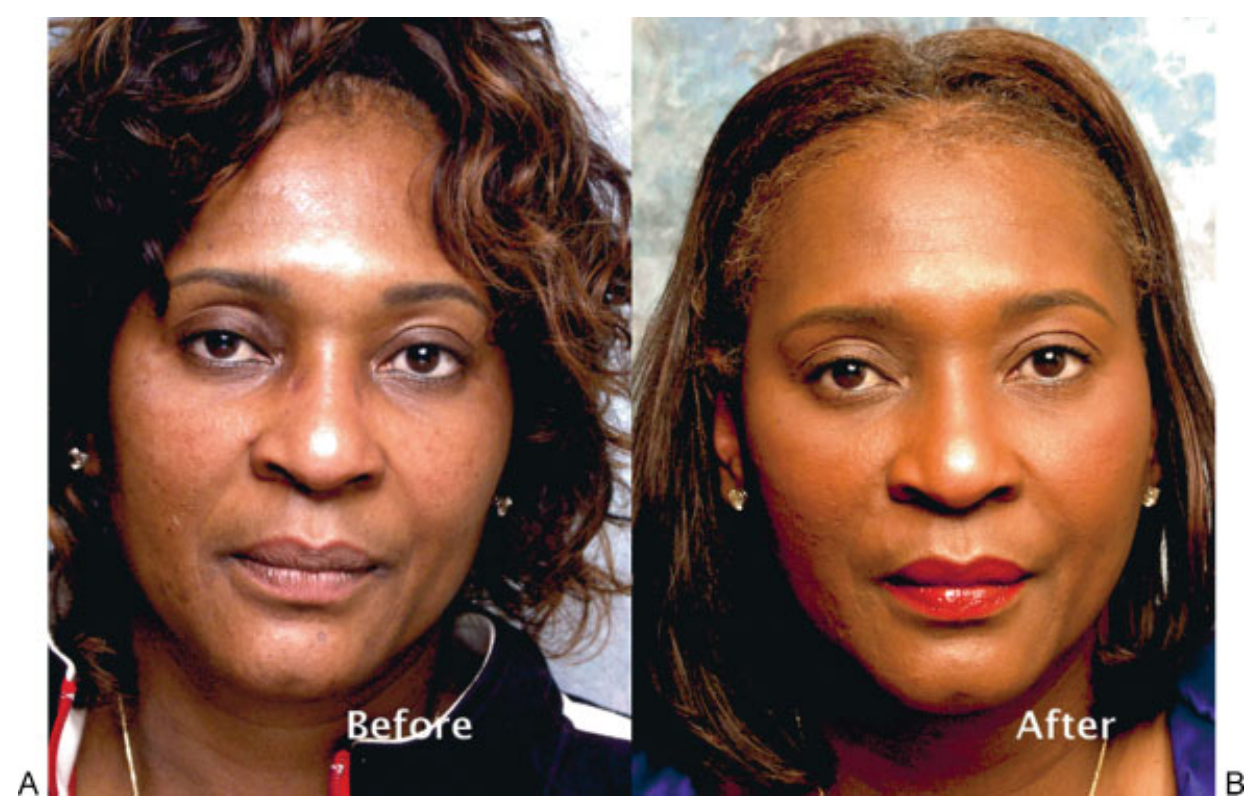

Figure 15 (A) Before photo of a 50-year-old woman who presented status post (s/p) 4 lid blepharoplasty with evidence of bilateral upper eyelid ptosis and bilateral lower eyelid hollowing. (B) After photo following bilateral upper eyelid ptosis repair and bilateral lower eyelid treatment with hyaluronic acid filler. (Kenneth D. Steinsapir M.D., Inc. is the copyright holder and permission is being granted to use the images.)

placing upward traction on the lower eyelid. The normal eyelid can be easily raised past the level of the pupil, whereas the lower eyelid with retraction will show evidence of restriction secondary to scarring of the orbital septum to the orbital rim.

Another clue to the diagnosis of lid retraction is that under normal circumstances the lateral canthal complex will move medially with eyelid closure, but with evidence of lower lid retraction, this movement will be decreased or even absent. Lid retraction is characterized by scarring, inflammation, shortening, and tethering of the middle and posterior lamellae resulting in vertical contraction of the eyelid with hollowing as the lower lid fat is pushed posteriorly into the orbit (-Fig. 17). Associated problems with lid retraction include scleral show, rounding of the lateral canthal, keratopathy, loss of the almond-shaped eye, and lagophthalmos.

Lower eyelid ectropion, defined as inferior malposition of the lower eyelid margin with eversion from the normal apposition to the globe, can occur independently or in combination with lower lid retraction. Excessive skin removal from a transcutaneous lower lid blepharoplasty can result in cicatricial ectropion, which is characterized by skin tautness with vertical skin tension lines, which worsen with mouth opening. A full-thickness skin graft may be required as part of the surgical correction. Risks of lower lid retraction/ectropion following lower eyelid blepharoplasty can be decreased by using a transconjunctival/pinch technique approach to avoid the orbital septum and therefore minimize possible middle lamellar inflammation/scarring or by emphasizing conservative skin removal if a transcutaneous technique is utilized. Another advantage of the transconjunctival approach is that the orbicularis muscle and its innervation are not compromised, thus dynamics of eyelid closure, including tear pumping and tear distribution are not affected. ${ }^{10}$

Initial management for lower lid retraction would include massaging the area of scar contraction and the use of lubricating agents and/or steroids. It is important that even if planning reconstructive surgery following complications from prior lid surgery, that the patient is treated with the above medical options while awaiting surgery. Canthopexy, canthoplasty, lateral retinacular suspension, or tarsal strip procedure can be used to correct lower lid laxity. ${ }^{54-84}$
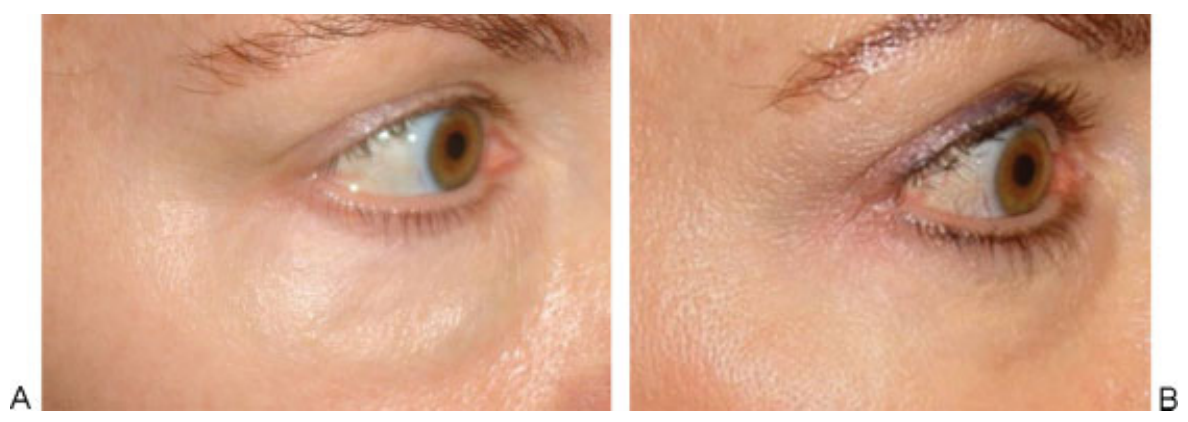

Figure 16 (A) Woman status post (s/p) hyaluronic acid dermal filler right lower eyelid; patient is unsatisfied with results from another physician. (B) Same patient after hyaluronidase treatment to right lower eyelid (Courtesy of John Fezza, M.D., with permission.) 


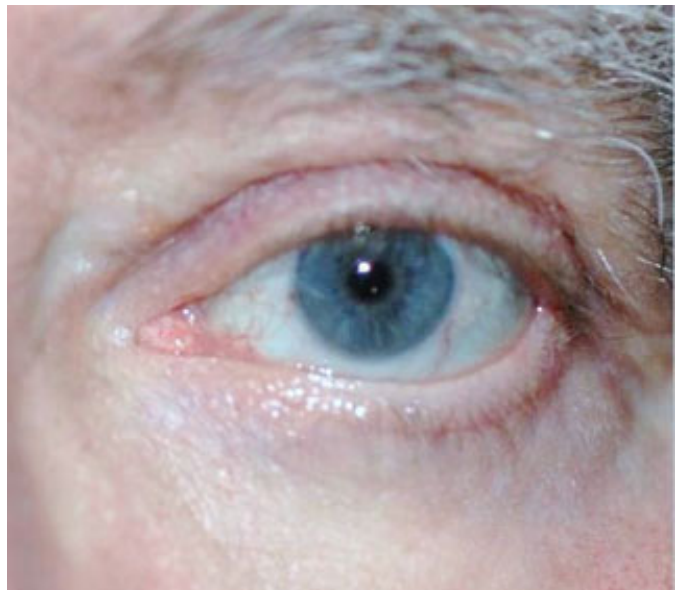

Figure 17 Patient with postoperative lower eyelid retraction with evidence of scleral show, lateral canthal dystopia, and periorbital hollowing.

Reattachment of the lower lid should be $1.5 \mathrm{~mm}$ inside the lateral orbital tubercle. Poor apposition to the globe will result if placed too anterior, if too posterior ocular irritation will may result, and poor cosmesis will occur if too superior or inferior. The surgeon should strive for the following: sharp lateral canthal angles, lid margin position at the level of the limbus, no override, and vertical symmetry with the level being at or slightly above the pupil.

The surgical repair of lower eyelid retraction will require not only correction of the lid laxity, but also the complete release of scar tissue with placement of a posterior lamellar spacer graft. All scarring and adhesions should be released so that the anterior and posterior lamellar are completely mobile to allow the orbital fat to reposition superiorly between the orbital septum and the capsulopalpebral fascia. Posterior lamellar spacer graft materials include auricular or nasal cartilage, porous polyethylene, sclera, tarsus, dermis fat, Enduragen (Stryker, Kalamazoo, MI), and hard palate mucosal and acellular dermal grafts ${ }^{85-93}$ (-Figs. 18, 19). Acellular dermal allografts avoid the morbidity of a second operational

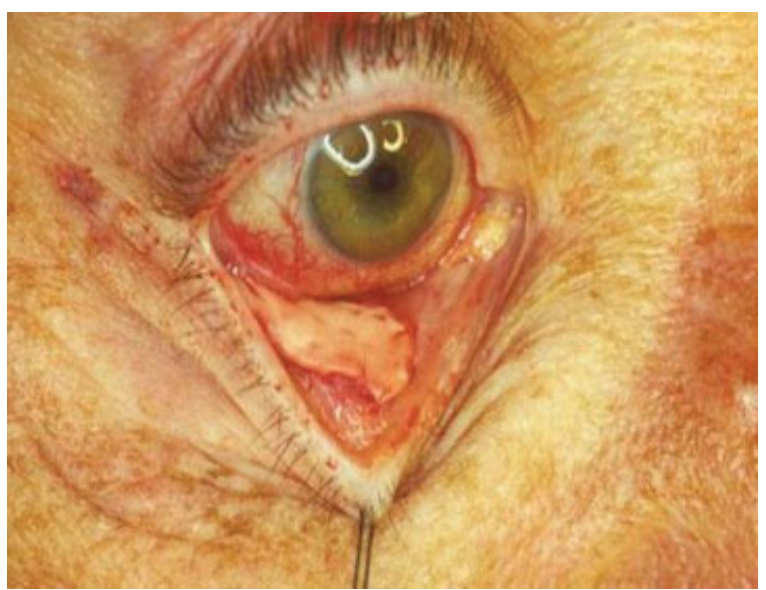

Figure 18 The surgical repair of lower eyelid retraction may require a transconjunctival approach to completely release the scar tissue so that the eyelid is freely mobile with placement of a spacer graft.
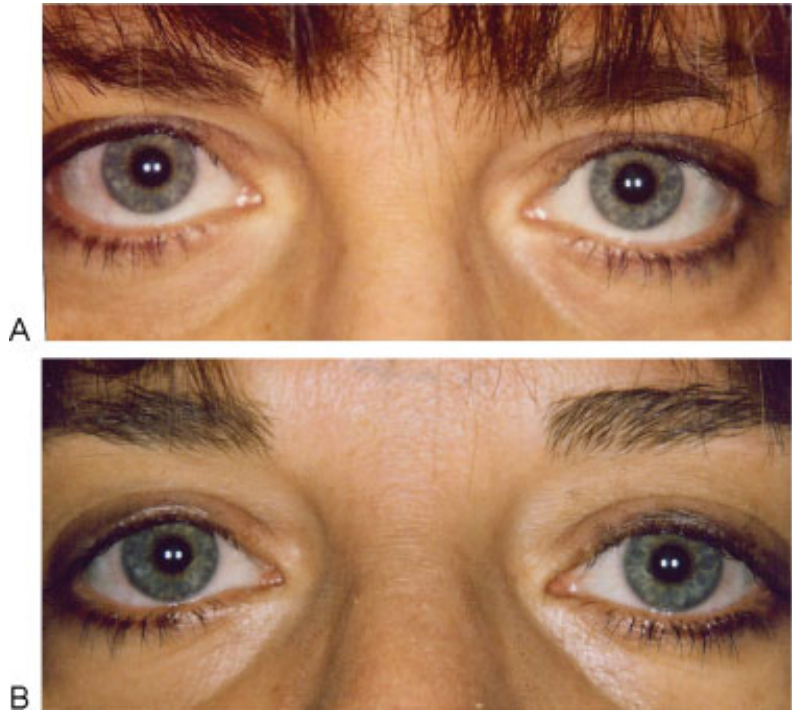

Figure 19 (A) Patient presents with postoperative lower eyelid retraction with evidence of scleral show, lateral canthal dystopia, and periorbital hollowing. (B) Same patient after transconjunctival release of scar tissue with placement of a spacer graft and lateral canthal anchoring.

site, as required with many of the above-mentioned grafts; however, there may be an increased contraction rate noted postoperatively. More severe cases of lower eyelid retraction may also require a midface lift in addition to the abovedescribed procedures. ${ }^{94-99}$

\section{Conclusion}

To avoid complications from eyelid surgery,both functional and/or cosmetic, the surgeon's examination of the patient should include a thorough evaluation of the brow/upper eyelid region to assess for the presence of brow ptosis, brow/eyelid asymmetry, and eyelid ptosis. The lower eyelid/cheek examination should focus on the diagnosis of underlying negative vector, dry eyes, prominent eyes, ectropion, lateral canthal dystopia, lower eyelid laxity, scleral show, lagophthalmos, chemosis, and lower eyelid retraction. Regarding the patient's past history, an emphasis should be placed on the previous diagnosis of dry eyes, past facial trauma, past injection of botulinum toxin and facial dermal fillers, and history of previous LASIK and previous facial surgery.

Early intervention during the postoperative period is important to correct any observed functional or cosmetic complications. Medical options should be utilized to treat dry eye syndrome and reduce ocular irritation during the postoperative period, even if the patient is scheduled to undergo revisional eyelid surgery. With upper and lower lid blepharoplasty, it is recommended that conservative skin/fat removal be emphasized with preservation of orbicularis muscle and its innervations. Regarding cosmetic eyelid surgery, the surgeon should strive to avoid skeletonization/hollowing/ deflation by repositioning and reinforcing tissue with an emphasis to restore fullness to achieve facial aesthetic balance between the forehead, eyelids, and midface. 


\section{References}

1 Lyon DB, Raphtis CS. Management of complications of blepharoplasty. Int Ophthalmol Clin 1997;37:205-216

2 Gausas RE. Complications of blepharoplasty. Facial Plast Surg 1999;15:243-253

3 Niamtu J III. Cosmetic blepharoplasty. Atlas Oral Maxillofac Surg Clin North Am 2004;12:91-130

4 Morax S, Touitou V. Complications of blepharoplasty. Orbit 2006;25:303-318

5 Hartstein ME, Kikkawa D. How to avoid blepharoplasty complications. Oral Maxillofac Surg Clin North Am 2009;21:31-41, v-vi

6 Solomon KD, Fernández de Castro LE, Sandoval HP II, Bartholomew LR, Vroman DT. Refractive surgery survey 2003. J Cataract Refract Surg 2004;30:1556-1569

7 Korn BS, Kikkawa DO, Schanzlin DJ. Blepharoplasty in the postlaser in situ keratomileusis patient: preoperative considerations to avoid dry eye syndrome. Plast Reconstr Surg 2007;119:2232-2239

8 Hester TR Jr, Douglas T, Szczerba S. Decreasing complications in lower lid and midface rejuvenation: the importance of orbital morphology, horizontal lower lid laxity, history of previous surgery, and minimizing trauma to the orbital septum: a critical review of 269 consecutive cases. Plast Reconstr Surg 2009;123: 1037-1049

9 Floegel I, Horwath-Winter J, Muellner K, Haller-Schober EM. A conservative blepharoplasty may be a means of alleviating dry eye symptoms. Acta Ophthalmol Scand 2003;81:230-232

10 Hamawy AH, Farkas JP, Fagien S, Rohrich RJ. Preventing and managing dry eyes after periorbital surgery: a retrospective review. Plast Reconstr Surg 2009;123:353-359

11 Vold SD, Carroll RP, Nelson JD. Dermatochalasis and dry eye. Am J Ophthalmol 1993;115:216-220

12 Moss SE, Klein R, Klein BE. Prevalence of and risk factors for dry eye syndrome. Arch Ophthalmol 2000;118:1264-1268

13 Toda I, Asano-Kato N, Komai-Hori Y, Tsubota K. Dry eye after laser in situ keratomileusis. Am J Ophthalmol 2001;132:1-7

14 Saadat D, Dresner SC. Safety of blepharoplasty in patients with preoperative dry eyes. Arch Facial Plast Surg 2004;6:101-104

15 Fagien S. Advanced rejuvenative upper blepharoplasty: enhancing aesthetics of the upper periorbita. Plast Reconstr Surg 2002;110: 278-291; discussion 292

16 Hass AN, Penne RB, Stefanyszyn MA, Flanagan JC. Incidence of postblepharoplasty orbital hemorrhage and associated visual loss. Ophthal Plast Reconstr Surg 2004;20:426-432

17 Pruthi RK. Five things oculoplastic surgeons should know about the preoperative assessment of hemostasis. Ophthal Plast Reconstr Surg 2002;18:396-401

18 Wolfort FG, Vaughan TE, Wolfort SF, Nevarre DR. Retrobulbar hematoma and blepharoplasty. Plast Reconstr Surg 1999;104: 2154-2162

19 Callahan MA. Prevention of blindness after blepharoplasty. Ophthalmology 1983;90:1047-1051

20 Goldberg RA, Marmor MF, Shorr N, Christenbury JD. Blindness following blepharoplasty: Two case reports and a discussion of management. Ophthalmic Surg 1990;21:81-89

21 Mahaffey PJ, Wallace AF. Blindness following cosmetic blepharoplasty-a review. Br J Plast Surg 1986;39:213-221

22 Putterman AM. Temporary blindness after cosmetic blepharoplasty. Am J Ophthalmol 1975;80:1081-1083

23 Jafek BW, Kreiger AE, Morledge D. Proceedings: blindness following blepharoplasty. Arch Otolaryngol 1973;98:366-369

24 Kelly PW, May DR. Central retinal artery occlusion following cosmetic blepharoplasty. Br J Ophthalmol 1980;64:918-922

25 Omoigui S, Irene S. Treatment of ptosis as a complication of botulinum toxin injection. Pain Med 2005;6:149-151

26 Wollina U, Konrad H. Managing adverse events associated with botulinum toxin type A: a focus on cosmetic procedures. Am J Clin Dermatol 2005;6:141-150
27 Huang W, Rogachefsky AS, Foster JA. Browlift with botulinum toxin. Dermatol Surg 2000;26:55-60

28 Huilgol SC, Carruthers A, Carruthers JDA. Raising eyebrows with botulinum toxin. Dermatol Surg 1999;25:373-375; discussion 376

29 Fagien S. Temporary management of upper lid ptosis, lid malposition, and eyelid fissure asymmetry with botulinum toxin type A. Plast Reconstr Surg 2004;114:1892-1902

30 Weinfeld AB, Burke R, Codner MA. The comprehensive management of chemosis following cosmetic lower blepharoplasty. Plast Reconstr Surg 2008;122:579-586

31 Cheng JH, Lu DW. Perilimbal needle manipulation of conjunctival chemosis after cosmetic lower eyelid blepharoplasty. Ophthal Plast Reconstr Surg 2007;23:167-169

32 Enzer YR, Shorr N. Medical and surgical management of chemosis after blepharoplasty. Ophthal Plast Reconstr Surg 1994;10:57-63

33 Sutcliffe RT. Chemosis following blepharoplasty. Ophthalmic Surg 1995;26:290-291

34 Thakker MM, Tarbet KJ, Sires BS. Postopertative chemosis after cosmetic eyelid surgery: Surgical management with conjunctiroplasty. Arch Facial Plast Surg 2005;7:185-188

35 Putterman AM. Regarding comprehensive management of chemosis following cosmetic lower blepharoplasty. Plast Reconstr Surg 2009;124:313-314

36 Flowers RS. Blepharoplasty. In: Courtiss EH, ed. Male Aesthetic Surgery. St. Louis, MO: CV Mosby; 1982

37 Leone CR. Treatment of a prolapsed lacrimal gland. In: Putterman AM, ed. Cosmetic Oculoplastic Surgery: Eyelid, Forehead, and Facial Techniques. 3rd ed. Philadelphia: W.B. Saunders Company; 1999:169-176

38 Beer GM, Kompatscher P. A new technique for the treatment of lacrimal gland prolapse in blepharoplasty. Aesthetic Plast Surg 1994;18:65-69

39 Baylis HI, Sutcliffe T, Fett DR. Levator injury during blepharoplasty. Arch Ophthalmol 1984;102:570-571

40 Burroughs JR, McLeish WM, Anderson RL. Upper blepharoplasty combined with levator aponeurosis repair. In: Fagien S, ed. Putterman's Cosmetic Oculoplastic Surgery. 4th ed. Philadelphia, PA: Saunders Elsevier; 2008:115-122

41 Putterman AM, Fagien S. Muller's muscle-conjunctival resectionptosis procedure combined with upper blepharoplasty. In: Fagien S, ed. Putterman's Cosmetic Oculoplastic Surgery. 4th ed. Philadelphia, PA: Saunders Elsevier; 2008:123-134

42 Goldberg RA. Fat repositioning in lower blepharoplasty. In: Fagien S, ed. Putterman's Cosmetic Oculoplastic Surgery. 4th ed. Philadelphia, PA: Saunders Elsevier; 2008:217-226

43 Trussler AP, Rohrich RJ. MOC-PSSM CME article: blepharoplasty. Plast Reconstr Surg 2008;121(1, Suppl):1-10

44 Redbord KP, Busso M, Hanke CW. Soft-tissue augmentation with hyaluronic acid and calcium hydroxylapatite fillers. Dermatol Ther 2011;24:77-81

45 Fitzgerald R, Graivier MH, Kane M, et al. Nonsurgical modalities to treat the aging face. Aesthet Surg J 2010;30(Suppl):31S-35S

46 Berbos ZJ, Lipham WJ. Update on botulinum toxin and dermal fillers. Curr Opin Ophthalmol 2010;21:387-395

47 Finn JC, Cox S. Fillers in the periorbital complex. Facial Plast Surg Clin North Am 2007;15:123-132, viii

48 Steinsapir KD, Steinsapir SM. Deep-fill hyaluronic acid for the temporary treatment of the naso-jugal groove: a report of 303 consecutive treatments. Ophthal Plast Reconstr Surg 2006;22: 344-348

49 Buckingham ED, Bader B, Smith SP. Autologous fat and fillers in periocular rejuvenation. Facial Plast Surg Clin North Am 2010;18: 385-398

50 Bray D, Hopkins C, Roberts DN. A review of dermal fillers in facial plastic surgery. Curr Opin Otolaryngol Head Neck Surg 2010;18: 295-302 
51 Lambros V. Volumizing the brow with hyaluronic acid fillers. Aesthet Surg J 2009;29:174-179

52 Goldberg RA, Fiaschetti B. Filling the periorbital hollows with hyaluronic acid gel: Initial experience with 244 injections. Ophthal Plast Reconstr Surg 2006;22:335-341

53 Fagien S, Carruthers J, Carruthers A. Injectable agents for dermal soft-tissue augmentation of the face: options and decision making. 4th ed. In: Fagien S, ed. Putterman's Cosmetic Oculoplastic Surgery. Boca Raton, FL: Saunders Elsevier; 2008:279-302

54 Tenzel RR, Buffam FV, Miller GR. The use of the "lateral canthal sling" in ectropion repair. Can J Ophthalmol 1977;12: 199-202

55 Schaefer AJ. Lateral canthal tendon tuck. Ophthalmology 1979;86: 1879-1882

56 Codner MA, McCord CD, Hester TR. The lateral canthoplasty. Oper Tech Plast Reconst Surg 1998;5:90

57 McCord CD Jr, Codner MA, Hester TR. Redraping the inferior orbicularis arc. Oper Tech Plast Reconst Surg 1998;102: 2471-2479

58 Fagien S. Algorithm for canthoplasty: The lateral retinacular suspension. A simplified suture canthopexy. Plast Reconstr Surg 1999; 103:2042

59 Flowers RS. Canthopexy as a routine blepharoplasty component. Clin Plast Surg 1993;20:351-365

60 Lowry JC, Bartley GB. Complications of blepharoplasty. Surv Ophthalmol 1994;38:327-350

61 Fagien S. Algorithm for canthoplasty: the lateral retinacular suspension: a simplified suture canthopexy. Plast Reconstr Surg 1999;103:2042-2053; discussion 2054-2058

62 Jelks GW, Jelks EB. Repair of lower lid deformities. Clin Plast Surg 1993;20:417-425

63 Glat PM, Jelks GW, Jelks EB, Wood M, Gadangi P, Longaker MT. Evolution of the lateral canthoplasty: techniques and indications. Plast Reconstr Surg 1997;100:1396-1405; discussion 1406-1408

64 Jelks GW, Glat PM, Jelks EB, Longaker MT. The inferior retinacular lateral canthoplasty: a new technique. Plast Reconstr Surg 1997;100:1262-1270; discussion 1271-1275

65 Marsh JL, Edgerton MT. Periosteal pennant lateral canthoplasty. Plast Reconstr Surg 1979;64:24-29

66 Patipa M. Lateral canthal tendon resection with conjunctiva preservation for the treatment of lower eyelid laxity during lower eyelid blepharoplasty. Plast Reconstr Surg 1993;91:456-462

67 Carraway JH. The role of canthoplasty in aesthetic blepharoplasty. Aesthet Surg J 1998;18:277

68 Rees TD. Prevention of ectropion by horizontal shortening of the lower lid during blepharoplasty. Ann Plast Surg 1983;11: $17-23$

69 Edgerton MT, Wolfort FG. The dermal-flap canthal lift for lower eyelid support. A technique of value in the surgical treatment of facial palsy. Plast Reconstr Surg 1969;43:42-51

70 Patipa M. The evaluation and management of lower eyelid retraction following cosmetic surgery. Plast Reconstr Surg 2000;106: 438-453; discussion 454-459

71 Millman AL, et al. The septomyocutaneous flap in lower lid blepharoplasty. Ophtalmol Plast Reconstr Surg 1997;13:2-6

72 McCord CD Jr, Shore JW. Avoidance of complications in lower lid blepharoplasty. Ophthalmology 1983;90:1039-1046

73 Hinderer UT. Correction of weakness of the lower eyelid and lateral canthus. Personal techniques. Clin Plast Surg 1993;20: 331-349

74 Anderson RL, Gordy DD. The tarsal strip procedure. Arch Ophthalmol 1979;97:2192-2196

75 Pak J, Putterman AM. Revisional eyelid surgery: treatment of severe postblepharoplasty lower eyelid retraction. Facial Plast Surg Clin North Am 2005;13:561-569, vi-vii
76 Hester TR Jr, Douglas T, Szczerba S. Decreasing complications in lower lid and midface rejuvenation: the importance of orbital morphology, horizontal lower lid laxity, history of previous surgery, and minimizing trauma to the orbital septum: a critical review of 269 consecutive cases. Plast Reconstr Surg 2009;123: 1037-1049

77 Lee AS, Thomas JR. Lower lid blepharoplasty and canthal surgery. Facial Plast Surg Clin North Am 2005;13:541-551, vi

78 Atiyeh BS, Hayek SN. Combined arcus marginalis release, preseptal orbicularis muscle sling, and SOOF plication for midfacial rejuvenation. Aesthetic Plast Surg 2004;28:197-202

79 Carraway JH, Grant MP, Lissauer BJ, Patipa M. Selection of canthopexy techniques. Aesthet Surg J 2007;27:71-79

80 Carraway JH, Coleman S, Kane MA, Patipa M. Periorbital rejuvenation. Aesthet Surg J 2001;21:337-343

81 Fagien S. Algorithm for canthoplasty: the lateral retinacular suspension: a simplified suture canthopexy. Plast Reconstr Surg 1999;103:2042-2053; discussion 2054-2058

82 Patipa M. Transblepharoplasty lower eyelid and midface rejuvenation: part I. Avoiding complications by utilizing lessons learned from the treatment of complications. Plast Reconstr Surg 2004;113:1459-1468; discussion 1475-1477

83 Patipa M. The evaluation and management of lower eyelid retraction following cosmetic surgery. Plast Reconstr Surg 2010; 106:438

84 Patipa M. Transblepharoplasty lower eyelid and midface rejuvenation: part II. Functional applications of midface elevation. Plast Reconstr Surg 2004;113:1459-1468; discussion 1475-1477

85 Kersten RC, Kulwin DR, Levartovsky S, Tiradellis H, Tse DT. Management of lower-lid retraction with hard-palate mucosa grafting. Arch Ophthalmol 1990;108:1339-1343

86 Rubin PA, Fay AM, Remulla HD, Maus M. Ophthalmic plastic applications of acellular dermal allografts. Ophthalmology 1999; 106:2091-2097

87 Korn BS, Kikkawa DO, Cohen SR, Hartstein M, Annunziata CC. Treatment of lower eyelid malposition with dermis fat grafting. Ophthalmology 2008;115:744-751, e2

88 Patel BC, Patipa M, Anderson RL, McLeish W. Management of postblepharoplasty lower eyelid retraction with hard palate grafts and lateral tarsal strip. Plast Reconstr Surg 1997;99:1251-1260

89 Tan J, Olver J, Wright M, Maini R, Neoh C, Dickinson AJ. The use of porous polyethylene (Medpor) lower eyelid spacers in lid heightening and stabilisation. Br J Ophthalmol 2004;88:1197-1200

90 Pang NK, Bartley GB, Bite U, Bradley EA. Hard palate mucosal grafts in oculoplastic surgery: donor site lessons. Am J Ophthalmol 2004;137:1021-1025

91 Oestreicher JH, Pang NK, Liao W. Treatment of lower eyelid retraction by retractor release and posterior lamellar grafting: an analysis of 659 eyelids in 400 patients. Ophthal Plast Reconstr Surg 2008;24:207-212

92 McCord C, Nahai FR, Codner MA, Nahai F, Hester TR. Use of porcine acellular dermal matrix (Enduragen) grafts in eyelids: a review of 69 patients and 129 eyelids. Plast Reconstr Surg 2008;122: 1206-1213

93 Pang NK, Bartley GB, Bite U, Bradley EA. Hard palate mucosal grafts in oculoplastic surgery: donor site lessons. Am J Ophthalmol 2004;137:1021-1025

94 Pak J, Putterman AM. Revisional eyelid surgery: treatment of severe postblepharoplasty lower eyelid retraction. Facial Plast Surg Clin North Am 2005;13:561-569, vi-vii

95 Hester TR, Codner MA, McCord CD. Subperiosteal malar cheek lift with lower blepharoplasty. In: McCord CD, Codner MA, and eds. Eyelid Surgery. Principles and Techniques. Philadelphia: Lippincott-Raven; 1995:210

96 Hester TR, Codner M, McCord CD. The "centrofacial" approach for facial aging using the transblepharoplasty subperiosteal cheek lift. Aesthetic Surg J 1996;16:51 
97 Gunter JP, Hackney FL. A simplified transblepharoplasty subperiosteal cheek lift. Plast Reconstr Surg 1999;103:2029-2035; discussion 2036-2041

98 Owsley JQJr, Zweifler M. Midface lift of the malar fat pad: technical advances. Plast Reconstr Surg 2002;110:674-685; discussion 686-687
99 Hester TR Jr, Codner MA, McCord CD, Nahai F, Giannopoulos A. Evolution of technique of the direct transblepharoplasty approach for the correction of lower lid and midfacial aging: maximizing results and minimizing complications in a 5-year experience. Plast Reconstr Surg 2000;105:393-406; discussion 407-408 